\title{
Blood Component Transfusion in a Tertiary Care Hospital
}

\author{
Mumtaz Sharif $^{1} \cdot$ Amit Saxena $^{1}$ (D) $\cdot$ Swati Singh ${ }^{1} \cdot$ Sundeep Manchala ${ }^{1} \cdot$ Neha Jafri ${ }^{1}$
}

Received: 30 April 2019 / Accepted: 2 January 2020 / Published online: 12 March 2020

(C) Dr. K C Chaudhuri Foundation 2020

\begin{abstract}
Objectives To study the rational use of the blood components in pediatric and neonatal wards.

Methods It was a retrospective study conducted by department of pediatrics of a tertiary care centre in western part of India. The patients were included from the pediatric ward, pediatric surgery ward, neonatal intensive care unit (NICU), pediatric intensive care unit (PICU) over a period of three months. All the patients below $12 \mathrm{y}$ of age receiving blood components, admitted in general pediatric wards, pediatric intensive care unit, neonatal intensive care unit and pediatric surgery ward were included in the study. Each transfusion episode was assessed as per predetermined guidelines.

Results Of the total 336 episodes of blood component transfusions, 244 episodes were appropriate and 92 episodes were inappropriate. Among these, platelets had highest inappropriate (36.84\%) episodes followed by fresh frozen plasma (FFP) $(28.95 \%)$ and packed red blood cell transfusions (PRBC) (21.21\%). Majority inappropriate transfusions were seen in intensive care settings.

Conclusions Almost one-third of blood component transfusions (FFP, platelets and PRBC) were given without any definitive indication. Judicious use of various blood products by following recommended guidelines may help in decreasing the inappropriate use of blood components.
\end{abstract}

Keywords Blood components · Transfusions · Audit

\section{Introduction}

Blood components are very often life saving health resources [1]. There is no substitute which has all the properties of human blood. However, the decision to transfuse blood components is also important as there are significant dangers associated with it.

The idea of blood transfusion appeared in the 15th and 16th centuries with the belief that the transfusion of the blood from a young and healthy person into an aged or debilitated individual would restore youth and health. With the discovery of blood group antigens in 1901, by Karl Landsteiner, transfusion therapy changed from a hazardous proposition to a relatively safe procedure [2]. During the last decade, the scenario of transfusion medicine has changed dramatically; with the advancement of technology, safety from transfusion transmitted disease has

Amit Saxena

dramitsaxena1981@gmail.com

1 Department of Pediatrics, D.Y. Patil Medical College, Nerul, Navi Mumbai 400706, India improved. Emphasis is also given on the use of specific blood components. However, the incidence of human-related adverse events, ABO incompatibility, alloimmunization, bacterial contamination, and immunomodulation phenomena are still a matter of concern [3].

Various guidelines have been formulated for judicious use of blood products [4-6] but despite the availability of these guidelines, a high rate of inappropriate use of blood and blood components has been reported around the world. However, studies done particularly in the pediatric age group are very few. With these backgrounds, the present study aims to assess the appropriateness of blood transfusion in pediatric population at authors' institute.

\section{Material and Methods}

This was a retrospective study conducted by the Department of Pediatrics in the pediatric ward, pediatric surgery, pediatric intensive care unit and neonatal intensive care unit of a tertiary care centre of western region of India. Approval of the institutional ethics committee was taken before initiating the study. The study was carried out over a period of 3 months and all 
episodes of transfusions occurring during that time in children below the age of 12 years were analyzed. Children with transfusion dependent disorder requiring repeated blood products transfusion were excluded from the study.

Information was entered on a pre-structured proforma which included the age of the patients, sex, diagnosis and indication for transfusion. Each transfusion was considered individually and analyzed for its appropriateness by using British Committee for Standards in Hematology (BCSH) guidelines for transfusion for packed red blood cell (PRBC), platelets and fresh frozen plasma in neonates and older children [6]. Appropriate transfusions were considered those which adhered to the guidelines of transfusion practices. Those which did not match the guidelines were deemed inappropriate and the results were analysed using appropriate statistical analysis.

\section{Results}

The present study recorded transfusion details of 315 patients receiving various blood components. There were a total of 336 episodes of transfusion of blood components among 315 patients from which 165 episodes $(49.1 \%)$ were of packed red cell transfusions (PRBC), 95 episodes (28.3\%) of platelet transfusions, 76 episodes $(22.6 \%)$ of fresh frozen plasma (FFP) and there were no episodes of cryoprecipitate transfusions in index study (Fig. 1).

Out of the total 336 transfusion episodes, 244 (72.6\%) were appropriate and 92 (27.4\%) were inappropriate (Fig. 2). There were 165 episodes of packed red cell transfusions. Of these, $130(78.79 \%)$ episodes were appropriate and $35(21.21 \%)$ were inappropriate. Platelets were the most frequently

\section{Episodes}

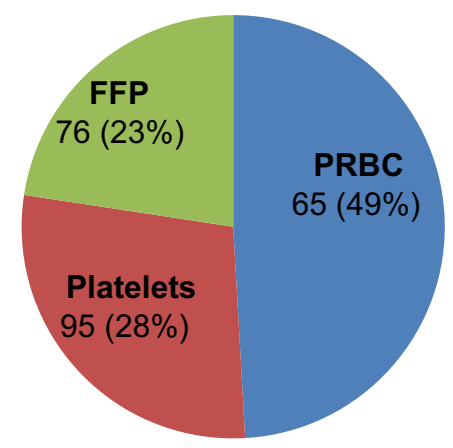

Fig. 1 Episodes of transfusions of blood components. FFP Fresh frozen plasma; PRBC Packed red blood cell inappropriately used blood component. Amongst the 95 episodes of platelet transfusions, 35 episodes $(36.84 \%)$ were categorized as inappropriate. Out of 76 episodes of fresh frozen plasma (FFP) transfusions studied, 22 episodes (28.95\%) were noted as inappropriate.

On assessing the appropriateness of blood components in the different settings of the pediatric patients (Table 1), it was found that neonatal intensive care unit (NICU) had the highest number of inappropriate transfusions (61) followed by pediatric intensive care unit (PICU) (25), pediatric surgery ward (4) and pediatric ward (2) out of the total 92 inappropriate transfusions. There was no statistical significance amongst the various pediatric settings in relation to transfusion. The $p$ value for pediatric ward could not be calculated due to insufficient sample size.

Table 2 shows the frequency of PRBC transfusion in accordance with the guidelines and its appropriateness. There were a total of 73 and 92 episodes of transfusions in neonates and older children respectively. Highest number of PRBC transfusion in neonates was given to those who were more than 2 wk of age and were on oxygen supplementation. It was followed by neonates who were less than 1 wk old both with and without requirement of oxygen with 14 episodes each. In older children the highest frequency of PRBC transfusion was seen in children with blood loss anemia (38 episodes) followed by children who had anemia with $\mathrm{Hb}<7 \mathrm{~g} / \mathrm{dl}$ and were stable, non-cyanotic admitted in PICU (25 episodes) and in pre-operative cases where the hemoglobin was less than $7 \mathrm{~g} / \mathrm{dl}$ (21 episodes). There was no significant correlation between indication and its appropriateness of PRBC transfusion in both neonates and older children.

As seen in Table 3, out of the 95 total platelet transfusions, 62 episodes of platelet transfusion were done in neonates and 33 in older children. Out of the 62 episodes, 24 episodes were in cases with platelet count of less than 1 lakh with major bleeding or requiring surgery followed by 22 transfusions in cases with severe thrombocytopenia of platelet less than 25,000 with no bleeding manifestation. Sixteen inappropriate transfusions were given for low platelet counts of less than 50,000 without signs of bleeding or coagulopathy. In older children majority of the transfusion episodes and also the inappropriate were done in patients with sepsis and DIC with platelet count of more than 20,000 . The $p$ value was not statistical significant between platelet transfusion and its appropriateness in neonates and older children.

There was a total of 76 FFP transfusions. A total of 42 episodes of transfusion were given to children with deranged coagulation profile, out of which, 14 episodes were in the absence of any bleeding manifestations and thus deemed inappropriate. Other indications for transfusion were thrombotic thrombocytopenic purpura or in children with hemolytic uremic syndrome or having an inherited bleeding disorder. Most 
Fig. 2 Appropriateness and inappropriateness of blood product transfusions. FFP Fresh frozen plasma; $P R B C$ Packed red blood cell

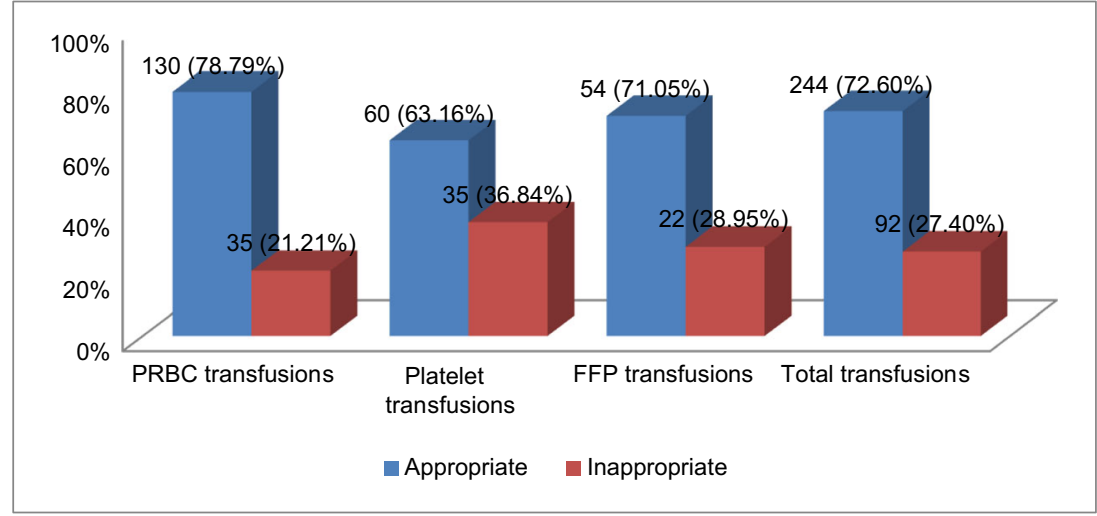

surgical patients with minor prolongation of coagulation profile without bleeding manifestations, were given inappropriate prophylactic transfusions (Table 4 ). There was a statistical significance $(p$ value $=0.00$ ) between FFP transfusion and its appropriateness.

\section{Discussion}

In recent years, a lot of advances have been made in the field of transfusion medicine making it more safer than before. However, inappropriate transfusion of blood and blood products exposes the patients to transfusion risks and also waste precious community resources [3].

Therefore the decision to transfuse blood or blood products must be based on careful clinical and laboratory indications. Hence to review the transfusion practices, this study was undertaken.

On analysing the PRBC transfusions, $79 \%$ were appropriate and $21 \%$ were inappropriate. There were 73 transfusions in NICU out of which $70 \%$ were appropriate and $30 \%$ were inappropriate. Most of them were transfused at higher threshold than recommended for indications like blood loss, sepsis and shock. This high percentage of inappropriate PRBC transfusion in sick patients can be explained by the fact that intensivists usually follow a liberal approach and keep a higher threshold for transfusion for aggressive management of patients. However, it should be kept in mind that newborn transfusions are not without risk.

In older children, out of the 92 episodes of transfusion, $86 \%$ were appropriate and $14 \%$ were inappropriate. The inappropriate transfusions were given in cases like dengue and prior to surgery even when the hemoglobin was at higher level than recommended. According to $\mathrm{BCSH}$ guidelines, PRBC transfusion is recommended in children with cardiopulmonary compromise or signs and symptoms suggestive of hypoxia due to low hemoglobin. If the child is stable, alternative measures to increase the hemoglobin can be offered thus reducing the risk of transfusion. An Indian study done in pediatric population by Wade et al. found $10 \%$ inappropriate whereas, similar study done by Bahadur et al. had $39 \%$ of inappropriate PRBC transfusions [7, 8]. Marti-carvajal et al. also found $76 \%$ appropriate PRBC transfusions in their study which was comparable to present findings [9].

Out of 95 episodes of platelet transfusions, $36.84 \%$ were inappropriate which was the highest amongst blood components. In NICU there were a total of 62 episodes of platelets transfusion; $58 \%$ were appropriate and $42 \%$ were inappropriate. Majority inappropriate transfusions $(45.7 \%)$ were given to patients with platelet count less than 50,000 without bleeding

Table 1 Distribution of inappropriate blood transfusion in different settings

\begin{tabular}{|c|c|c|c|c|c|c|c|c|}
\hline & \multicolumn{2}{|l|}{ Surgery ward } & \multicolumn{2}{|c|}{ Pediatric ward } & \multicolumn{2}{|l|}{ NICU } & \multicolumn{2}{|l|}{ PICU } \\
\hline & Appropriate & Inappropriate & Appropriate & Inappropriate & Appropriate & Inappropriate & Appropriate & Inappropriate \\
\hline PRBC & 30 & 2 & 2 & 2 & 51 & 22 & 47 & 9 \\
\hline Platelets & 8 & 1 & 0 & 0 & 36 & 26 & 16 & 8 \\
\hline FFP & 5 & 1 & 0 & 0 & 29 & 13 & 20 & 8 \\
\hline Total & 43 & 4 & 2 & 2 & 116 & 61 & 83 & 25 \\
\hline Chi square & 0.800 & & - & & 2.366 & & 3.438 & \\
\hline$p$ value & 0.67 & & - & & 0.30 & & 0.18 & \\
\hline
\end{tabular}

FFP Fresh frozen plasma, NICU Neonatal intensive care unit, $P I C U$ Pediatric intensive care unit, $P R B C$ Packed red blood cell 
Table 2 Indications of PRBC therapy and its appropriateness

\begin{tabular}{|c|c|c|c|c|c|}
\hline Indication (With anemia) & Appropriate $[n(\%)]$ & Inappropriate $[n(\%)]$ & $\begin{array}{l}\text { Number of } \\
\text { components }\end{array}$ & Chi Square & $P$ value \\
\hline Neonates & & & & 8.3798 & 0.59 \\
\hline \multicolumn{6}{|l|}{ Off Oxygen Supplementation } \\
\hline$<1$ wk with $\mathrm{Hb}<10 \mathrm{~g} / \mathrm{dl}$ & $4(66.7)$ & $2(33.3)$ & 6 & & \\
\hline$>2$ wk with $\mathrm{Hb}<7.5 \mathrm{~g} / \mathrm{dl}$ & $7(50)$ & $7(50)$ & 14 & & \\
\hline \multicolumn{6}{|l|}{ On Oxygen Supplementation } \\
\hline $24 \mathrm{~h}$ with $\mathrm{Hb}<12 \mathrm{~g} / \mathrm{dl}$ & $1(100)$ & 0 & 1 & & \\
\hline$<1$ wk with $\mathrm{Hb}<10 \mathrm{~g} / \mathrm{dl}$ & $12(85.7)$ & $2(14.3)$ & 14 & & \\
\hline$>2$ wk with $\mathrm{Hb}<9.5 \mathrm{~g} / \mathrm{dl}$ & $15(79)$ & $4(21)$ & 19 & & \\
\hline$>3$ wk with $\mathrm{Hb}<8.5 \mathrm{~g} / \mathrm{dl}$ & $3(100)$ & 0 & 3 & & \\
\hline \multicolumn{6}{|l|}{ On Ventilatory Support } \\
\hline$<1$ wk ventilated with $\mathrm{Hb}<12 \mathrm{~g} / \mathrm{dl}$ & $3(50)$ & $3(50)$ & 6 & & \\
\hline$>2 \mathrm{wk}$ on ventilator with $\mathrm{Hb}<10 \mathrm{~g} / \mathrm{dl}$ & $6(60)$ & $4(40)$ & 10 & & \\
\hline Total & $51(70)$ & $22(30)$ & 73 & & \\
\hline Older children & & & & 17.455 & 0.06 \\
\hline $\mathrm{Hb}<7 \mathrm{~g} / \mathrm{dl}$ stable, non-cyanotic in PICU & $25(100)$ & 0 & 25 & & \\
\hline $\begin{array}{l}\mathrm{Hb}>7 \mathrm{~g} / \mathrm{dl} \text { hemodynamically unstable or } \\
\text { symptomatic anemia }\end{array}$ & $7(87.5)$ & $1(12.5)$ & 8 & & \\
\hline \multicolumn{6}{|l|}{ Surgical } \\
\hline $\begin{array}{l}\mathrm{Hb}<7 \mathrm{~g} / \mathrm{dl} \text { in stable without major bleeding and } \\
\text { comorbidity }\end{array}$ & $14(66.7)$ & $7(33.3)$ & 21 & & \\
\hline Blood loss & $33(86.8)$ & $5(13.2)$ & 38 & & \\
\hline Total & $79(85.9)$ & $13(14.1)$ & 92 & & \\
\hline Grand total & $130(78.9)$ & $35(21.21)$ & 165 & & \\
\hline
\end{tabular}

manifestations. This was mostly in septic newborns where transfusion was given with the thought of preventing severe bleed. Out of 33 transfusions in older children, 9 episodes were inappropriate $(27 \%)$, which is in trend with the study done by Ahmed and Save in PICU in western India [10].
Eight out of nine inappropriate transfusions were in patients with platelet count of 20,000 with no bleed and most cases were of Dengue and sepsis. Various studies on pediatric blood transfusion audits done have reported $7 \%$ to $33 \%$ of platelet transfusions to be inappropriate $[7,8,11]$.

Table 3 Indication for platelet transfusion and its appropriateness

\begin{tabular}{|c|c|c|c|c|c|}
\hline Indication & Appropriate $[n(\%)]$ & Inappropriate $[n(\%)]$ & $\begin{array}{l}\text { Number of } \\
\text { components }\end{array}$ & Chi square & $p$ value \\
\hline Neonates & & & & 52.429 & 9.35 \\
\hline$<25,000$ with no bleeding & $22(100)$ & 0 & 22 & & \\
\hline$<50,000$ with bleeding, coagulopathy, before surgery & 0 & $16(100)$ & 16 & & \\
\hline$<100,000$ with major bleeding or requiring surgery & $14(58.3)$ & $10(41.6)$ & 24 & & \\
\hline Total & $36(58.1)$ & $26(41.9)$ & 62 & & \\
\hline \multicolumn{6}{|l|}{ Children } \\
\hline$<10,000$ with no bleed & $2(100)$ & 0 & 2 & \multirow[t]{4}{*}{5.0276} & \multirow[t]{4}{*}{0.88} \\
\hline$<20,000$ with sepsis or DIC & $11(57.9)$ & $8(72.7)$ & 19 & & \\
\hline $\begin{array}{l}<50,000 \text { moderate hemorrhage in association } \\
\text { with DIC or surgery }\end{array}$ & $11(91.6)$ & $1(8.4)$ & 12 & & \\
\hline Total & $24(72.7)$ & $9(27.3)$ & 33 & & \\
\hline Grand total & 60 & $35(36.8)$ & 95 & & \\
\hline
\end{tabular}

DIC Disseminated intravascular coagulation 
Table 4 Indications for FFP transfusion and its appropriateness

\begin{tabular}{|c|c|c|c|c|c|}
\hline Indication & $\begin{array}{l}\text { Appropriate } \\
{[n(\%)]}\end{array}$ & $\begin{array}{l}\text { Inappropriate } \\
{[n(\%)]}\end{array}$ & $\begin{array}{l}\text { Number of } \\
\text { components }\end{array}$ & $\begin{array}{l}\text { Chi } \\
\text { square }\end{array}$ & $\begin{array}{l}P \\
\text { value }\end{array}$ \\
\hline Significant bleeding with deranged coagulation & $28(66.7)$ & $14(33.33)$ & 42 & 30.6218 & $0.00 *$ \\
\hline $\begin{array}{l}\text { Thrombotic thrombocytopenic purpura and hemolytic uremic syndrome or inherited } \\
\text { bleeding disorder }\end{array}$ & $24(100)$ & 0 & 24 & & \\
\hline \multicolumn{6}{|l|}{ Surgical } \\
\hline $\begin{array}{l}\text { Prophylactic FFP administered to non-bleeding children with minor prolongation of } \\
\text { the prothrombin time/activated partial thromboplastin time }\end{array}$ & 0 & $8(100)$ & 8 & & \\
\hline $\begin{array}{l}\text { FFP in children with DIC who have a significant coagulopathy (PT/APTT }>1.5 \text { times } \\
\text { midpoint of normal range or fibrinogen }<1.0 \mathrm{~g} / \mathrm{L} \text { ) associated with clinically } \\
\text { significant bleeding or prior to invasive procedures }\end{array}$ & $2(100)$ & 0 & 2 & & \\
\hline Total & $54(71.1)$ & $22(28.9)$ & 76 & & \\
\hline
\end{tabular}

APTT Activated partial thromboplastin time, DIC Disseminated intravascular coagulation, FFP Fresh frozen plasma, $P T$ Partial thromboplastin *significant $p$ value $<0.05$

The present study also recorded $71.1 \%$ appropriate and $28.9 \%$ inappropriate FFP transfusions. It was mainly given in critical patients with altered gastric aspirate and minor bleeding at prick site with deranged coagulation profile. However, the guidelines clearly mention the use of FFP with significant bleeding and deranged coagulation profile. FFP were also given preoperatively in patients with altered coagulation profile and no bleeding manifestation but guidelines state that FFP should not be administered to children with minor prolongation of coagulation profile. Similar studies done by Shinagare et al. and Kulkarni et al. showed inappropriate use of FFP as $39 \%$ and $52 \%$ respectively $[12,13]$, which is much higher than present study. Most transfusions were seen in ICU settings in septic and shock patients.

Even as the majority of blood component transfusions were appropriate, inappropriate transfusions were noted in intensive care settings where clinicians tend to be more aggressive to transfuse considering the variability of underlying diagnosis and physiologic stability. However, clinician must keep in mind that there is an increased risk of morbidity and mortality in intensive care patient undergoing transfusions [14-16].

\section{Conclusions}

This audit done showed that almost a-third of transfusions were inappropriate and a need to follow guidelines before taking a decision to transfuse is emphasized. Nevertheless, in ICU settings, clinical judgement can trump guidelines at times and hence classifying them completely inappropriate is debatable. Since, it was a retrospective study, the relevance of the time of issue (whether in routine duty of staff or emergency hours/preholiday) with inappropriate transfusions could not be assessed.
Authors' Contribution MS: Conceptualizing, analysis of results, editing and manuscript writing; AS: Conceptualizing, analysis of results and editing; SS and SM: Compilation of data; NJ: Analysis of results. MS is the guarantor for this paper.

\section{Compliance with Ethical Standards}

Conflict of Interest None.

\section{References}

1. World Health Organization. Blood Transfusion Safety Team. The Clinical Use of Blood: Handbook. Geneva: WHO; 2001.

2. Sturgis CC. The history of blood transfusion. Bull Med Libr Assoc. 1942;30:105-12.

3. Bhattacharya P, Marwaha N, Dhawan HK, Roy P, Sharma RR. Transfusion-related adverse events at the tertiary care center in North India: an institutional hemovigilance effort. Asian J Transfus Sci. 2011;5:164-70.

4. Bansal D. Transfusion medicine and component therapy. In: Parthasarathy A, Menon PSN, Gupta P, editors. IAP Textbook of Pediatrics, 5th ed. Gwalior: Jaypee Publishers; 2013. p. 707-12.

5. Kumar S, Ravikumar KG, Ramachandran B. Bleeding child in PICU. In: Khilani P, Deepak U, Ramachandran B, editors. IAP Textbook of Pediatric ICU Protocols, 2nd ed. Gwalior: Jaypee Publishers; 2013. p. 157-60.

6. New H, Berryman J, Bolton-Maggs P, et al. Guidelines on transfusion for fetuses, neonates and older children. Br J Haematol. 2016;175:784-828.

7. Wade M, Sharma R, Manglani M. Rational use of blood components - an audit. Indian J Hematol Blood Transfus. 2009;25:66-9.

8. Bahadur S, Sethi N, Pahuja S, Pathak C, Jain M. Audit of pediatric transfusion practices in a tertiary care hospital. Indian J Pediatr. 2015;82:333-9.

9. Marti-Carvajal AJ, Muñoz-Navarro SR, Martí-Peña AJ, et al. Appropriate use of blood products in pediatric patients in a Venezuelan General University hospital: cross-sectional study. Salus. 2005;9:20-30.

10. Ahmed M, Save SU. Blood component therapy in pediatric intensive care unit in tertiary care center: an audit. Int J Contemp Med Res. 2016;3:1506-10.

11. Bhat A, Aziz R, Ahmed C, Ahmed S. Utility of blood components in paediatric patients. An audit. [Internet]. Alliedacademies.org. 
2019. Available at: http://www.alliedacademies.org/articles/utilityof-blood-components-in-paediatric-patients-an-audit.pdf. Accessed 28 Feb 2019.

12. Shinagare SA, Angarkar NN, Desai SR, Naniwadekar MR. An audit of fresh frozen plasma usage and effect of fresh frozen plasma on the pre-transfusion international normalized ratio. Asian $\mathrm{J}$ Transfus Sci. 2010;4:128-32.

13. Kulkarni N. Evaluation of fresh frozen plasma usage at a medical college hosiptal- a two year study. Int J Blood Transfus Immunohematol. 2012;2:16-20.

14. Rajasekaran S, Kort E, Hackbarth R, et al. Red cell transfusions as an independent risk for mortality in critically ill children. J Intensive Care. 2016;4:2.
15. Du Pont-Thibodeau G, Tucci M, Robitaille N, Ducruet T, Lacroix J. Platelet transfusions in pediatric intensive care. Pediatr Crit Care Med. 2016;17:e420-9.

16. Murad MH, Stubbs JR, Gandhi MJ, et al. The effect of plasma transfusion on morbidity and mortality: a systematic review and meta-analysis. Transfusion. 2010;50:1370-83.

Publisher's Note Springer Nature remains neutral with regard to jurisdictional claims in published maps and institutional affiliations. 